\title{
Nuevos métodos anticonceptivos masculinos
}

\section{Artícullo de revisión}

Delgado-Sánchez Jonathan Dazaeth*, González-Durán Dominic*, Aguayo-Llamas Cristina Jenissia*, Muñoz Flores-Cadena Gustavo*, Ruvalcaba-Landeros José Roberto*, Rangel-Martínez Itzel Celic*, Rosas-Rosales Edmundo*, Huitrón-Castro Nadia**

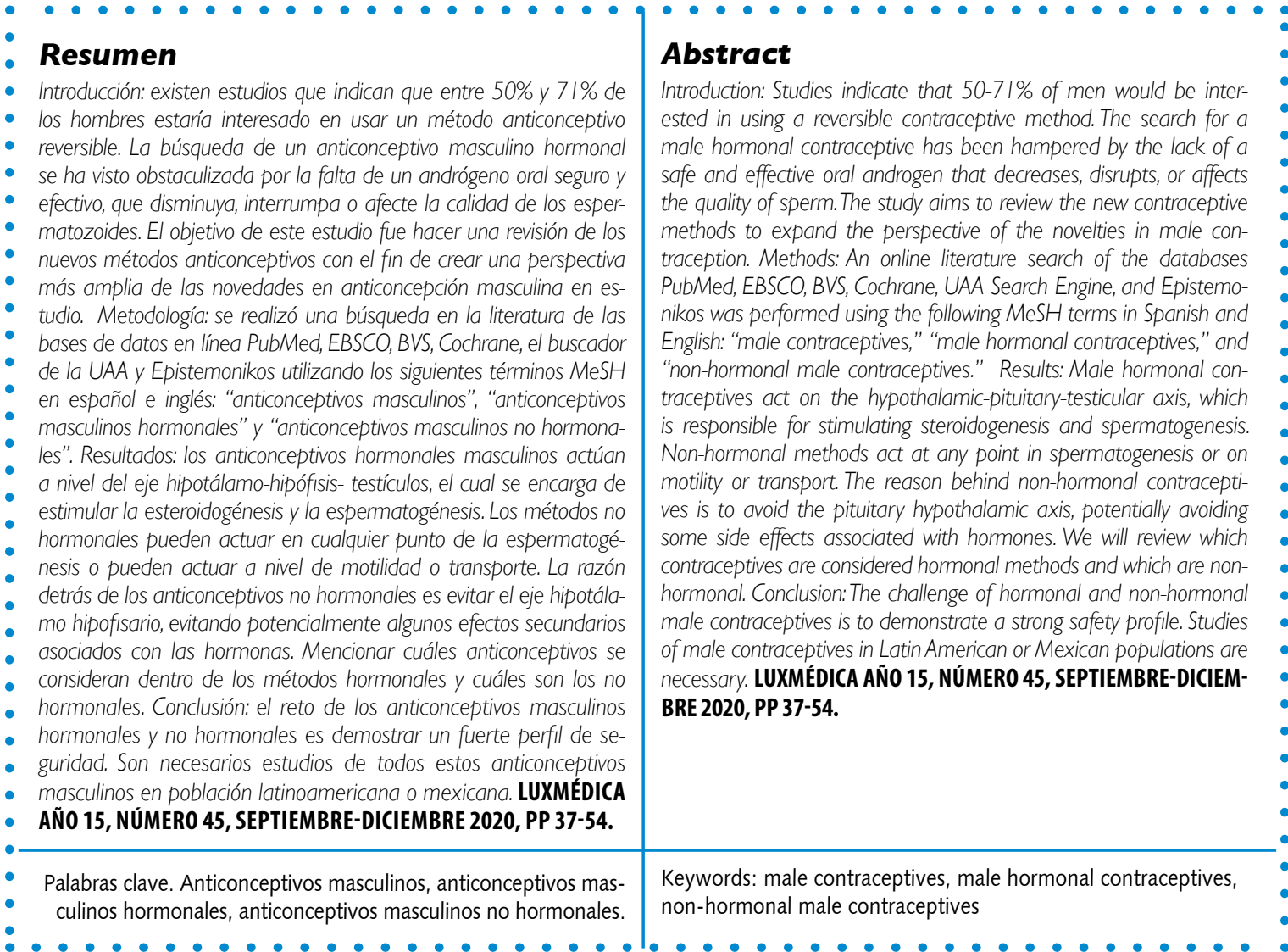

\footnotetext{
Estudiante del noveno semestre de la Carrera de Médico Cirujano del Centro de Ciencias de la Salud de la Universidad Autónoma de Aguascalientes, México. Presidente de la Sociedad Aguascalentense de Estudiantes de Medicina 2019-2020. Correo electrónico dazaethsanchez@gmail.com ORCID: https://orcid.org/0000-0002-9917-9973

Estudiante del noveno semestre de la Carrera de Médico Cirujano del Centro de Ciencias de la Salud de la Universidad Autónoma de Aguascalientes México.

Correo electrónico: drdadu@gmail.com ORCID: https://orcid.org/0000-0003-0668-7598

Estudiante del noveno semestre de la Carrera de Médico Cirujiano del Centro de Ciencias de la Salud de la Universidad Autónoma de Aguascalientes. México. Correo electrónico: jenissia 97@hotmail.com Estudiante del noveno semestre de la Carrera de Médico Cirujano del Centro de Ciencias de la Salud de la Universidad Autónoma de Aguascalientes, México. Correo electrónico gustavo.kdena@gmail.com ORCID: Estudiante del noveno semestre de la $\mathrm{C}$

Estudiante del noveno semestre de la Carrera de Médico Cirujiano del Centro de Ciencias de la Salud de la Universidad Autónoma de Aguascalientes, México. Correo electrónico: garob 15@hotmail.com

Estudiante del noveno semestre de la Carrera de Médico Cirujiano del Centro de Ciencias de la Salud de la Universidad Autónoma de Aguascalientes, México. Correo electrónico itzeel Imtz@ hotmail.com ORCID. Estudiant//orcidorg/0000-0003-1345-9710

Estudiante del noveno semestre de la Carrera de Médico Ciruiano del Centro de Ciencias de la Salud de la Universidad Autónoma de Aguascalientes, México. Correo electrónico: edmundo.rosas.@@outlookcon Especialista en Medicina Interna. Profesor Investigador de la Carrera de Médico Cirujano del Centro de la Ciencia de la Salud de la Universidad Autónoma de Aguascalientes. Correo electrónico: nadia.hc@hotmail.con

Fecha de recibido: 8 de junio de 2020

Fecha de aceptación: 8 de agosto de 2020

Correspondencia

Dra Nadia Huitrón Castro. Departamento de Medicina edificio 107, planta alta. Centro de Ciencias de la Salud. Campus Universitario. Universidad Autónoma de Aguascalientes. Avenida Universidad 940 . Código Postal 20131.
} Aguascalientes, Ags. México. Teléfono 449 9108443. Correo electrónico nadia.hc@hotmail.com 


\section{Introducción}

Los condones masculinos y la abstinencia son los únicos métodos anticonceptivos reversibles disponibles en el mercado para los hombres, con tasas de fallas típicas de $13 \%$ y $20 \%$ respectivamente. ${ }^{1,2}$ Los estudios indican que entre $50 \%$ y $71 \%$ de los hombres estaría interesado en usar un método reversible, si estuviera disponible ${ }^{3}, y$ muchas mujeres estarían dispuestas a confiar en su pareja para usar un anticonceptivo masculino (AM). ${ }^{4}$

Los anticonceptivos se pueden clasificar de diferentes maneras, principalmente por su duración o por su componente hormonal. Cuando se aborda por su duración, tenemos anticonceptivos reversibles de corta duración (ARCD), anticonceptivos reversibles de larga duración (ARLD) y la anticoncepción definitiva. Como ya se mencionó, los únicos ARCD masculinos son los condones masculinos; actualmente no hay ARLD para hombres en el mercado. ${ }^{5}$ La vasectomía es generalmente considerada como una opción de método definitivo con dificultades de reversión. También se cuenta con clasificación hormonal y no hormonal de los anticonceptivos, que será la empleada en este estudio. La búsqueda de un anticonceptivo masculino hormonal $(\mathrm{AMH})$ se ha visto obstaculizada por la falta de un andrógeno oral seguro y efectivo, que es un componente necesario para el método. Mientras que la búsqueda de un anticonceptivo masculino no hormonal (AMNH) tiene el reto de encontrar el componente que disminuya, interrumpa o afecte la calidad de los espermatozoides y su maduración. Las investigaciones sobre la AM ha girado en torno a métodos hormonales y no hormonales con la eficacia y seguridad de suprimir la producción de esperma, perturbar la maduración o función de los espermatozoides, o alterar el transporte o la motilidad de los espermatozoides, ${ }^{6}$ dichas investigaciones se encuentran en desarrollo activo (Tabla 1). ${ }^{7}$ El objetivo de este estudio fue hacer una revisión de los nuevos métodos anticonceptivos masculinos con el fin de crear una perspectiva más amplia de las novedades en anticoncepción masculina en estudio.

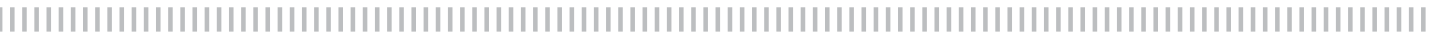

\section{Material y métodos}

Se realizó una búsqueda en la literatura de las bases de datos en línea PubMed, EBSCO, BVS, Cochrane, Buscador UAA y Epistemonikos, utilizando los siguientes términos MeSH en español e inglés: "anticonceptivos masculinos", "anticonceptivos masculinos hormonales" y "anticonceptivos masculinos no hormonales". Los resultados de la búsqueda se limitaron a artículos de texto completo, revisiones narrativas, revisiones sistemáticas, estudios en sujetos humanos y animales escritos en el idioma inglés publicado entre el 1 de enero de 2015 y el 1 de abril de 2020.

En la búsqueda inicial en las 6 bases de datos, se encontró un total de 242 artículos, de los cuales 23 eran duplicados, dejando un total de 219 artículos únicos. Después de aplicar los criterios de exclusión mencionados en la figura 1, se descartaron 157 artículos. De los 62 artículos para esta revisión se realizó una revisión detallada utilizando las listas de cotejo PRISMA, STROBE, ARRIVE, 


\section{Tabla I}

\section{Cuadro comparativo de los métodos anticonceptivos masculinos 5,6,8-11}

$\mathbf{A M}^{*}$

\begin{tabular}{|c|c|c|}
\hline \multicolumn{3}{|c|}{ Anticonceptivos masculinos de barrera } \\
\hline WLM $^{*}$ & $\begin{array}{l}\text { - No se necesita la erección del pene para } \\
\text { colocarse. } \\
\text { - Se adhiere a toda la región de la ingle, incluyendo } \\
\text { testículos. } \\
\text { Tasa de fracaso clínico } 0 \% \text { (ruptura } 0 \% \text {; } \\
\text { deslizamiento } 0 \% \text { ). }\end{array}$ & $\begin{array}{l}\text { - Requiere lubricación externa. } \\
\text { - Extracción dolorosa. }\end{array}$ \\
\hline WLC $^{*}$ & $\begin{array}{l}\text { No se necesita la erección del pene para } \\
\text { colocarse. } \\
\text { Se adhiere al eje del pene. } \\
\text { Tasa de fracaso clínico } 0.52 \% \text { (ruptura } 0.52 \% \text {; } \\
\text { deslizamiento } 0 \% \text { ). }\end{array}$ & $\begin{array}{l}\text { - Necesita lubricación externa. } \\
\text { Extracción dolorosa. } \\
\quad \text { Mayor aceptación que el WLM }\end{array}$ \\
\hline
\end{tabular}

Anticonceptivos masculinos no hormonales

\begin{tabular}{|c|c|c|c|c|}
\hline Nest-T* & • & $\begin{array}{l}\text { Actúa a nivel del eje } \mathrm{HHT}^{*} \text { manteniendo debajo } \\
\text { del umbral normal los niveles de TT } \\
\text { Gel combinado de nestorona y testosterona. } \\
\text { Suprime la concentración de esperma a } 1 \text { millón / } \\
\text { ml o azoospermia en el } 89 \% \text { de hombres } \\
\text { Reversible. }\end{array}$ & $\bullet$ & $\begin{array}{l}\text { Afectos adversos; dolor en la inyección ( } 4-23 \%) \text {, } \\
\text { acné }(7-46 \%) \text { aumento de hematocrito }(1 \%) \text {, } \\
\text { aumento de peso ( } 4-24 \%) \text {, cambios de humor (1- } \\
24 \%) \text {, cambios en la libido ( } 4-42 \%) \text {, cambios de } \\
\text { comportamiento }(1-6 \%) \text { y fatiga }(2-8 \%) \text {. }\end{array}$ \\
\hline DMAU* & $\begin{array}{l}\bullet \\
\bullet \\
\bullet\end{array}$ & $\begin{array}{l}\text { Una testosterona modificada capaz de unirse a los } \\
\text { receptores de andrógenos y de progesterona. } \\
\text { No es susceptibles a } 5 \text { alfa reductasa. } \\
\text { Se administra oral o intramuscular. } \\
\text { Reversible. }\end{array}$ & & $\begin{array}{l}\text { Los efectos adversos; dolor de cabeza (19- } \\
29 \%) \text {, infección de vía respiratoria superior } \\
(23 \%) \text {, acné }(16 \%) \text {, cambios de humor }(16 \%) \text {, } \\
\text { fatiga ( } 13 \%) \text {, incremento subjetivo de peso } \\
(10 \%) \text {, decrecimiento de lívido }(11-16 \%) \text {, } \\
\text { decrecimiento de erección }(10 \%) \text { y reducción de } \\
\text { HDL-C. }\end{array}$ \\
\hline \multicolumn{5}{|c|}{ Anticonceptivos masculinos no hormonales } \\
\hline EPPIN & • & $\begin{array}{l}\text { Fuerte actividad antibacteriana y modula actividad } \\
\text { proteolítica del PSA* contra su sustrato seminal en } \\
\text { plasma. } \\
\text { Inhibe motilidad de los espermatozoides. } \\
\text { Capa adicional de protección en el tracto } \\
\text { reproductor femenino. } \\
\text { Reversible. }\end{array}$ & $\bullet$ & $\begin{array}{l}\text { Solo se ha estudiado en modelos biológicos de } \\
\text { primates y ratones. }\end{array}$ \\
\hline Vasalgel $^{\mathrm{TM}}$ & $\bullet$ & $\begin{array}{l}\text { El dispositivo se inyecta dentro del conducto } \\
\text { deferente para impedir que los espermatozoides } \\
\text { transiten a través del conducto deferente }\end{array}$ & $\bullet$ & $\begin{array}{l}\text { Solo se ha estudiado en modelos biológicos de } \\
\text { conejos. }\end{array}$ \\
\hline DBAD & $\bullet$ & $\begin{array}{l}\text { Actúa a nivel de la vía del AR. } \\
\text { Reversible }\end{array}$ & $\bullet$ & Reacción de disulfiram severa. \\
\hline JQ1 & ? & $\begin{array}{l}\text { Inhibidor de BRDT* } \\
\text { Inhibe la primera división meiótica de la } \\
\text { espermatogénesis. } \\
\text { Reversible. }\end{array}$ & $\bullet$ & $\begin{array}{l}\text { Solo se ha estudiado en modelos biológicos de } \\
\text { ratones. }\end{array}$ \\
\hline RISUG* & $\begin{array}{l}\bullet \\
\bullet \\
\bullet\end{array}$ & $\begin{array}{l}\text { Copolímero de SMA* reaccionado con DMSO } \\
\text { inyectado en conductos deferentes. } \\
\text { Oclusión de los vasos deferentes y disminuye pH } \\
\text { afectando movilidad de espermatozoides. } \\
\text { Azoospermia a los dos meses post aplicación. } \\
\text { Reversible. }\end{array}$ & & $\begin{array}{l}\text { Aumento leve del escroto por edema difuso } \\
\text { escrotal en la primera semana de aplicación. } \\
\text { Se sigue estudiando el uso de otros solventes } \\
\text { diferentes a DMSO*. }\end{array}$ \\
\hline $\mathrm{CE}^{*}$ & • & $\begin{array}{l}\text { CE de } 24-167 \times 106 \text {. } \\
\text { Tasa de motilidad fue del } 30-95 \% \text {. } \\
\text { Proporción morfológica espermática normal del } \\
13-45 \% \text {. } \\
\text { Reversibilidad a los tres de suspensión del } \\
\text { tratamiento. } \\
\text { Reversible. }\end{array}$ & $\bullet$ & $\begin{array}{l}\text { No se identificaron efectos adversos después del } \\
\text { tratamiento con calentamiento escrotal en } \\
\text { ninguno de los pacientes. } \\
\text { Se necesitan más estudios con un periodo de } \\
\text { seguimiento superior al presente. }\end{array}$ \\
\hline A25-O* & & $\begin{array}{l}\text { Inhibición especifica de la } \mathrm{Na}, \mathrm{K}-\mathrm{ATP} \text { asa } a 4 \text { y de } \\
\text { la función espermática. } \\
\text { Reversible }\end{array}$ & & $\begin{array}{l}\text { Solo se ha estudiado en modelos biológicos de } \\
\text { ratones. }\end{array}$ \\
\hline
\end{tabular}

*Anticonceptivos masculinos (AM), WondaleafCap® (WLC), Wondaleaf-On-Man® (WLM), Gel de nestorona-testosterona (Nest-T), Undecanoato de dimetandrolona (DMAU), lipoproteínas de alta densidad, inhibidor de la proteasa epididimaria (EPPIN)m antígeno prostático (PSA), hipotálamo-hipofisiario-testicular (HHT), testosterona testicular (TT), Análogo de bisdicloroacetildiaminas (DBAD), ácido retinoico (AR), proteínas especificas del bromodominio testicular (BRDT), Inhibición reversible de esperma bajo guía (RISUG), dimetilsulfóxido (DMSO), calentamiento escrotal (CE), análogo 25 de ouabagenina (A25-0). 
CONSORT y Narrative Review Checklist, además de un análisis de riesgo de sesgo de las publicaciones seleccionadas. Posterior a esta revisión detallada se excluyeron 31 artículos. Durante el análisis de la información obtenida se agregaron por búsqueda manual de las referencias de los estudios incluidos un total de 9 artículos (figura 1).
Dado que el objetivo principal del estudio fue hacer una revisión de los nuevos anticonceptivos en el mercado y estudio además del condón masculino tradicional, las características de los condones masculinos en el mercado estaban fuera del alcance de este estudio y, por lo tanto, no se discutieron.

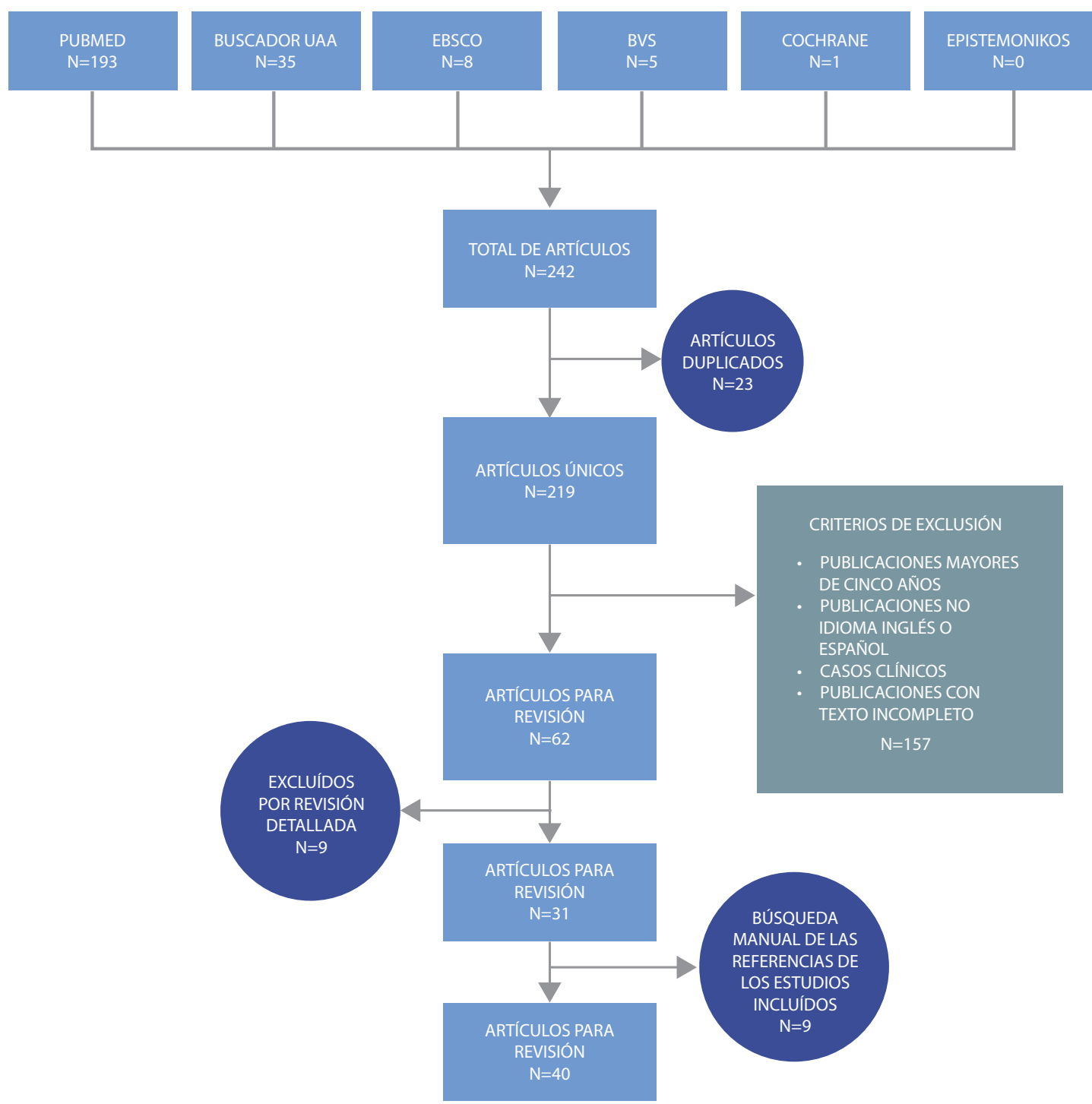

Fig. 1. Anticonceptivos masculinos de barrera, hormonales y no hormonales. Flujograma del proceso de selección de estudios. 


\section{Resultados}

\section{Anticonceptivos de barrera. Condones adhesivos sintéticos masculinos}

Los métodos de barrera tendrán, en el futuro previsible, un papel importante en la prevención de infecciones. Los nuevos materiales y métodos de producción están aumentando la diversidad de condones disponibles en el mercado con el objetivo de mejorar la sensación mientras se mantiene la seguridad y la eficacia. ${ }^{12}$ A pesar de su efectividad, los problemas persistentes de los condones masculinos son debido a la posibilidad de deslizamiento, rotura y potencial alergénico. Para abordar estos problemas, los condones masculinos adhesivos sintéticos (SAMC por sus siglas en inglés) se han desarrollado desde $1980 .{ }^{13}$

Los dos SAMC que se encuentran en desarrollo son clasificados como "WondaleafCap ${ }^{\circ}$ " (WLC) y "Wondaleaf-On-Man ${ }^{\circledR}$ " (WLM). El primero tiene un recubrimiento adhesivo en la abertura del condón para pegarse en el eje del pene, mientras que el último tiene un escudo adhesivo integral que se adhiere a la pelvis del usuario. ${ }^{5}$ Los condones externos Wondaleaf permiten a los usuarios ponerse el dispositivo sin la necesidad de la erección del pene, lo que permite el despliegue preventivo antes de la actividad sexual (figura 2).

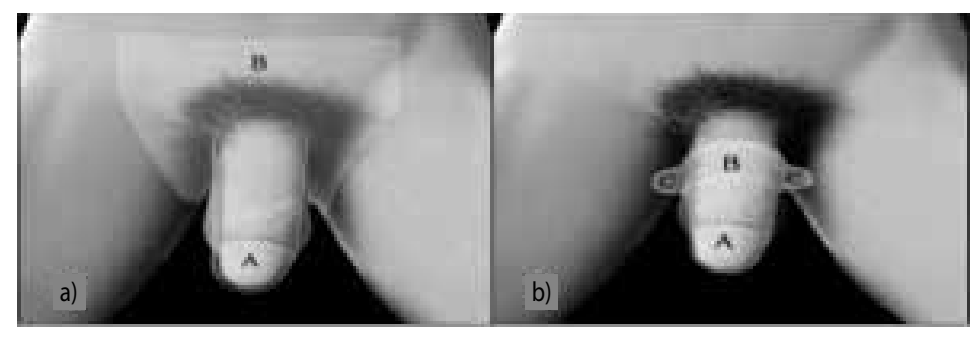

Fig. 2. Ilustraciones de condones de estudio (Wondaleaf-On-Man, Wondaleaf-Cap y Durex-Together); a) Se muestra el Wondaleaf-On-Man debidamente desplegado en el pene. La porción del condón (A) cubre sin apretar el pene, mientras que la cubierta adhesiva integral $(B)$ se adhiere a toda la región de la ingle (incluidos los testículos); $b$ ) Wondaleaf-Cap debidamente desplegado en el pene. El condón holgado (A) cubre el glande, mientras que el escudo adhesivo se adhiere al eje del pene (B) y a sí mismo para formar la parte proximal del condón $(B)$ y dos pestañas laterales respectivamente. Las pestañas que sobresalen lateralmente son suaves y delgadas.

WLM está hecho de $0.02 \mathrm{~mm}$ de grosor de una película de poliuretano. Originalmente se desarrolló como un condón femenino; para usar en el hombre, la bolsa se convierte en una funda suelta sobre el pene y un protector adhesivo extendido que cubre el área de la ingle completa, incluidos los testículos. No tiene lubricación, está di- señado para usarse con un lubricante externo que se incluye en una bolsita de $8 \mathrm{ml}$ con cada condón. El escudo adhesivo de WLC es aplicado directamente en el eje del pene formando la parte proximal del condón. El usuario remueve el condón sosteniendo las pestañas en el costado desliza dispositivo y tirando el condón distalmente con contra- 
presión en la piel del pene. El lubricante viene incluido en el dispositivo. ${ }^{5}$

En un estudio clínico se analizaron los AM de barrera WLC, WLM y Durex ${ }^{\circledR}$-Together (DT). En este estudio las tasas de fracaso clínico de WLC, WLM y DT fueron $0.52 \%$ (ruptura $0.52 \%$; deslizamiento $0.52 \%$ ), $0 \%$ (ruptura $0 \%$; deslizamiento $0 \%$ ) y $0.52 \%$ (ruptura $0.52 \%$, deslizamiento $0 \%$ ) respectivamente. Las tasas de fracaso no clínico de WLC, WLM y DT fueron del 2,08\%, 3.12\% y $1.04 \%$, respectivamente. La extracción fue más dolorosa con los productos Wondaleaf que con el DT. Las preferencias de los participantes para WLC, WLM y DT fueron $33.3 \%, 29.2 \%$ y $25 \%$, respectivamente. En general, WLC y DT tuvieron mayores aceptaciones entre los participantes masculinos que WLM. ${ }^{5}$ Se necesitan más estudios para la eliminación del dolor y su relación con el rendimiento sexual.

\section{Anticonceptivos masculinos hormonales}

Los anticonceptivos hormonales masculinos $(A H M)$, actúan a nivel del eje hipotálamohipófisis- testículos, el cual se encarga de estimular la esteroidogénesis y la espermatogénesis. La espermatogénesis comienza en el cerebro, el hipotálamo secreta $\mathrm{GnRH}$, la cual estimulará a la pituitaria para producir FSH y LH. La FSH y LH actúan a nivel de las células de Sertoli y de Leydig. Las células de Leydig son las encargadas de la producción de testosterona. ${ }^{12}$

Una hormona esteroide exógena, como un andrógeno, una combinación de andrógenos y progestágenos, o un antagonista de la hormona liberadora de gonadotropina ${ }^{14}$ puede suprimir la liberación de FSH y LH en la hipófisis; el resultado de esta supresión es una baja concentración de LH y FSH, lo que provoca una reducción en la producción de testosterona intratesticular y la diferenciación de las espermatogonias. ${ }^{15}$ En hombres sanos, las concentraciones de testosterona testicular son de 40 a $100 \mathrm{ng} / \mathrm{dl} 2$ más altas que las concentraciones plasmáticas de testosterona. Esta concentración intratesti- cular es necesaria para mantener el equilibro necesario para la ejecución de la espermatogénesis. Por debajo de estos umbrales de testosterona testicular, no se produce la producción de esperma. Sin embargo, otras funciones de dependientes de andrógenos como libido, la erección, la eyaculación y el mantenimiento de la masa muscular depende de suficientes concentraciones de testosterona en suero. ${ }^{2,16}$ Los estudios que utilizan este enfoque han mostrado altas tasas de oligozoospermia severa (1 millón/ml) o azoospermia (sin esperma), lo que resulta en una alta eficacia anticonceptiva con pocos efectos secundarios informados. ${ }^{13,15}$

El papel esencial de la GnRH en la regulación de la función reproductiva lo convierte en un objetivo obvio para el estudio de los $\mathrm{AMH}$. Tanto los agonistas como los antagonistas tienen el potencial de actuar como anticonceptivos. Los agonistas de la GnRH no producen una supresión suficiente de la gonadotropina en los hombres, pero los antagonistas de la GnRH son muy efectivos y se han realizado varios estudios investigado los antagonistas de la GnRH (con testosterona); sin embargo, éstos no redujeron las concentraciones de esperma en mayor grado que las combinaciones de testosteronaprogestágeno. ${ }^{14}$ Los antagonistas de $\mathrm{GnRH}$ sólo han estado disponibles en preparaciones parenterales que requieren inyecciones en serie o infusiones, lo que tiene implicaciones prácticas y de costo.

\section{Gel de nestorona-testosterona}

La producción local de testosterona en las pruebas se observa una concentración de testosterona testicular a niveles que son mayores que las de suero, con una alta concentración local soportando la espermatogénesis. Múltiples estudios de eficacia anticonceptiva han demostrado que la testosterona inyectable sola o en combinación con una progestina tiene un 95\% de eficacia anticonceptiva. ${ }^{17}$ La administración de testosterona exógeno con o sin una progestina actúa sobre la retroalimentación 
negativa en el eje hipotálamo hipofisiario para suprimir gonadotropinas resultando en la represión de la producción de testosterona testicular debajo de un umbral necesario para soportar la espermatogénesis. ${ }^{18} \mathrm{Si}$ la inhibición es mantenida por una progestina, un reemplazo exógeno de testosterona es necesario para las funciones andrógeno dependientes diferente a la producción de esperma. ${ }^{9,15}$

La efectividad de este tipo de anticoncepción radica en la inhibición del eje hipotálamo-hipófisis-gonadal, al utilizar de manera exógena una combinación de nestorona y testosterona. La nestorona contiene acetato de segesterona una nueva progestina que se une específicamente a los receptores de progesterona. En los primeros estudios del uso de gel Nestorone (8 $\mathrm{mg}$ ) y gel testosterona (100 mg) suprimieron la concentración de esperma a 1 millón/ml o azoospermia en el $89 \%$ de hombres en comparación con sólo el $23 \%$ de los hombres que usaron gel de testosterona y un gel placebo. Las concentraciones de la hormona gonadotropina que fueron de $1 \mathrm{UI} / \mathrm{L}$ después de 4 semanas de tratamiento predijeron el fracaso del tratamiento (concentración de esperma $1 \mathrm{mi}$ llón/ml) con un $97 \%$ de sensibilidad diagnóstica. ${ }^{19}$

En un estudio clínico se evaluó la efectividad de la administración de un gel combinado con nestorona $8.3 \mathrm{mg}$ y $62.5 \mathrm{mg}$ de testosterona en $5 \mathrm{ml}$ (Nest-T), versus la aplicación de un gel que sólo contenía testosterona en la misma dosis de $62.5 \mathrm{mg}$ en $4.4 \mathrm{ml}$ ambos durante 28 días, esto con el fin de ver cuál tiene mejor eficacia en suprimir las concentraciones séricas de FSH y LH $\mathrm{a} \leq 1.0 \mathrm{UI} / \mathrm{L}$, las cuales son concentraciones conocidas que tienen un buen efecto anticonceptivo en hombres. ${ }^{20}$ Los resultados que encontraron fueron que las concentraciones séricas de FSH y LH fueron significativamente más suprimidas en el grupo de gel Nes-T en comparación con el grupo de gel testosterona en el día 7 de tratamiento y permanecieron significativamente más suprimidas durante el resto del período de tratamiento de 28 días y hasta el día 2 del periodo de recuperación, también las gonadotropinas séricas ya no se suprimieron significativamente en el grupo de gel Nes-T en comparación con el grupo de gel testosterona en el tercer día de recuperación.

Mahavadi y cols. aplicaron un gel transdérmico de Nes-T pero con distinta posología, la cual fue nestorona (6-8 mg / día) con un gel T (10 g / día) durante 20 días, el cual demostró también una supresión efectiva de FSH y LH. Los efectos adversos encontrados en este estudio fueron efectos androgénicos en algunos participantes, incluido el acné ( $21 \%$ de los participantes), aumento del hematocrito (del 1\%) y aumento de peso leve (de 2 a $5 \mathrm{~kg} ; 7 \%$ del total de participantes). ${ }^{21}$

Actualmente se está realizando un gran ensayo de eficacia de fase IIb de un gel transdérmico combinado Nes-T en 10 centros en 4 continentes, en el cual además se busca la eficacia en las concentraciones de gonadotropinas. ${ }^{7}$ Los resultados mostraron que la aplicación del gel combinado Nes-T puede ser un buen $\mathrm{AMH}$, ya que suprime las concentraciones séricas de $\mathrm{FSH}$ y $\mathrm{LH}(\leq 1.0 \mathrm{UI} / \mathrm{L})$ asociado con la anticoncepción hormonal masculina altamente efectiva. ${ }^{20,21}$ Los efectos secundarios más comunes en los hombres, con este método, se resumen en una revisión reciente, en todos los estudios de eficacia. Éstos incluyen problemas relacionados con la inyección, como dolor (4-23\%), acné (7$46 \%$ ), aumento de peso $4-24 \%$, cambios de humor (1-24\%), cambios en la libido (4$42 \%$ ), cambios de comportamiento (1-6\%) y fatiga $(2-8 \%){ }^{7}$

\section{Undecanoato de dimetandrolona (DMAU)}

Undecanoato de dimetandrolona $(7 \alpha, 11 \beta$ dimetil-19-nortestosterona undecanoato) por sus siglas (DMAU), es una testosterona modificada capaz de unirse a los receptores de andrógenos (AR) y de progesterona $(P R)^{22,23}$ dándole a DMAU el potencial de actuar como una "píldora anticonceptiva" 
de un solo agente sin la necesidad de administrar dos hormonas. No es susceptible a 5 alfa reductasa. Cuando se administra oral o intramuscular, el DMAU es hidrolizado por la forma activa del dimetandrolona, un derivado de 19-nortestosterona que se une a los receptores de andrógenos y progesterona, tolerado en estudios de fase uno. ${ }^{24}$

Se ha demostrado en algunos estudios que la testosterona y las gonadotropinas en suero se suprimieron a niveles consistentes con la anticoncepción efectiva, y la mayoría de los hombres que recibieron 400 $\mathrm{mg}$ /día suprimiendo $\mathrm{LH}$ y $\mathrm{FSH}$ a $<1 \mathrm{UI} / \mathrm{ml}$ y $\mathrm{T}$ a $<10 \mathrm{ng} / \mathrm{dl}$. A pesar de estos niveles de testosterona en suero, se han observado pocos participantes en los estudios con síntomas significativos relacionados con la disminución de la concentración de testosterona los cuales son: disminución de la libido, disfunción eréctil, astenia e irritabilidad. Sin embargo, hubo efectos secundarios androgénicos limitados con la administración diaria de DMAU, incluyendo aumento de peso (1.5 a $3.8 \mathrm{~kg})$, eritrocitosis ( 0.4 a $2 \%$ ) y reducción en el colesterol de lipoproteínas de alta densidad (HDL-C) (6 a $15 \mathrm{mg} / \mathrm{dl}$ ). ${ }^{15}$

En un estudio clínico aleatorizado doble ciego en dos centros médicos en el que pacientes masculinos sanos (18-50 años) fueron asignados al azar para recibir placebo oral o 11ßMNTDC, 200 o $400 \mathrm{mg}$ al día, durante 28 días consecutivos. En algunos estudios el evento adverso más común ocurre en $>5 \%$ de todos los participantes fue el dolor de cabeza 19-29\%, infección de vía respiratoria superior $23 \%$, acné $16 \%$, cambios de humor $16 \%$, fatiga $13 \%$, incremento subjetivo de peso $10 \%$, decrecimiento de la libido $11-16 \%$, y decrecimiento de erección 10\%. La muestra de 31 pacientes vs 11 placebo, en el placebo no hubo de fatiga a falta de erecciones. Otros efectos adversos como náuseas, elevación de lípidos y transaminasas, seborrea, crecimiento anormal de vello ocurrieron en menos de $<5 \%$ de todos los participantes. ${ }^{18,25}$

En un estudio en el que se evaluó una dosis oral única (hasta $800 \mathrm{mg}$ ), se observó un efecto de dosis significativo para el peso, hematocrito, colesterol de lipoproteínas de alta densidad, intervalo QT corregido y deseo sexual, así como concentraciones séricas promedio de 24 horas de DMAU y DMA mostró aumentos relacionados con la dosis $(P, 0.001) .{ }^{25}$ El 11ß-MNTDC resultó en una dosis relacionada aumento de las concentraciones séricas de 11ß-MNTDC y 11ß-MNT sostenidas durante $24 \mathrm{~h}$. La administración de 11ß-MNTDC resultó en una marcada supresión del suero gonadotropinas, testosterona, testosterona libre calculada, E2 y SHBG durante el período de tratamiento $(p<0.01)^{7,25}$

En los estudios no se encontraron eventos adversos graves y ningún participante suspendió su uso debido a un evento adverso o anormalidad en la prueba de laboratorio. Todos llegan a la conclusión de que el tratamiento ha demostrado resultados óptimos para más pruebas e investigaciones. ${ }^{22-25}$

\section{Anticonceptivos masculinos no hormonales}

Los métodos anticonceptivos masculinos no hormonales (AMNH) pueden actuar en cualquier punto de la espermatogénesis o pueden actuar a nivel de motilidad o transporte. La razón detrás de los $\mathrm{AMNH}$ es evitar el eje hipotálamo hipofisario, y disminuir potencialmente algunos efectos secundarios asociados con las hormonas, involucrando proteínas dirigidas que afectan la producción o la función de espermatozoides, estos anticonceptivos se encuentran en la fase preclínica actualmente. ${ }^{16,26,27}$

\section{Inhibidor de la proteasa epididimaria (EPPIN)}

El inhibidor de la proteasa epididimaria (EPPIN) es un gen dependiente de andrógenos, expresado abundantemente en los testículos y epidídimo, pero también se encuentra en el conducto deferente, la vesícula seminal y la glándula suprarrenal. Se discute 
como un ejemplo de desarrollo de nuevos anticonceptivos utilizando la inmunización de primates. Por ello se busca una alternativa estudiando EPPIN, un inhibidor de proteasa ependimaria, junto con semenogelin (SEMG1). ${ }^{26}$ Se han estudiado tres funciones fisiológicas de EPPIN: la primera es que exhibe una fuerte actividad antibacteriana y modula la actividad proteolítica del PSA (antígeno prostático específico) contra su sustrato seminal de plasma, SEMG1. La segunda es que el EPPIN inhibe la motilidad de los espermatozoides cuando se une SEMG1 en la superficie del esperma. Y la tercera función fisiológica es que actúa como una capa adicional de protección en el tracto reproductor femenino previniendo la hiperactivación prematura y capacitación. ${ }^{2,28}$

En un estudio, a través de un modelo biológico de ratón, se ha analizado la distribución de EPPIN en los espermatozoides de ratón que se modula dinámicamente en el epidídimo. El ratón es un modelo experimental adecuado para estudios traslacionales de EPPIN como fármaco para la anticoncepción masculina. Los espermatozoides maduros presentaron tinción de EPPIN en la cabeza y flagelo. La inmunoprecipitación de EPPIN de espermatozoides preincubados con vesícula seminal fluido (SVF) seguido de LC-MS / MS o Western blot reveló la coinmunoprecipitación de SVS2, SVS3A, SVS5 y SVS6. ${ }^{28}$ Los enfoques de transferencia in silico y Far-Western demostraron que EPPIN une SVS2 en una red de proteínas con otras proteínas SVS. Inmunofluorescencia y con el uso de los espermatozoides preincubados con SVF o SVS2 recombinante, demostraron la localización conjunta de EPPIN y SVS2 tanto en la cabeza del esperma como en el flagelo. Los roles de EPPIN en el esperma tienen las funciones que se conservan entre el mouse y el humano, lo que demuestra que el ratón es un modelo experimental para estudios traslacionales en EPPIN. 2,28

\section{Vasalgel $^{\mathrm{Tm}}$}

El Vasalgel ${ }^{\mathrm{TM}}$ es un dispositivo que se inyecta dentro del conducto deferente para impedir que los espermatozoides transiten a través de éste. El implante permanece en un suave gel, con la capacidad de adaptarse al interior luz del conducto deferente y minimizar cualquier acomodación de éste a la presencia del material. ${ }^{6}$ Eso forma un hidrogel que permite el tránsito de moléculas hidrosolubles pero no estructuras más grandes, como los espermatozoides. En el estudio en el que se utilizaron conejos como modelo animal, se inyectó bicarbonato de sodio en los vasos deferentes luego de catorce meses de azoospermia después de la inyección de dos variaciones del dispositivo (Vasalgel 100 y Vasalgel 80). Luego se recolectaron muestras de semen durante seis meses y las características de los espermatozoides se compararon con los niveles basales. En los resultados la concentración de esperma y la motilidad de los espermatozoides fue similar a los niveles basales después de la inversión, mientras que la progresión hacia adelante de los espermatozoides fue significativamente menor y no se observaron acrosomas normales. Histológicamente varios vasos deferentes estaban libres del dispositivo y contenían un revestimiento epitelial intacto. Una proporción menor de los tejidos contenían material de prueba residual. Una respuesta inflamatoria intraluminal secundaria se observó ocasionalmente en los tejidos que contienen material residual. No hubo diferencia entre las dos variaciones de dispositivo para los parámetros del estudio. 2,6,16 Se realizaron mediciones para determinar si los valores habían vuelto a la normalidad. La concentración de esperma no fue significativamente diferente entre el valor basal y el post-basal $(p<0.31)$ (figura 3 ). 


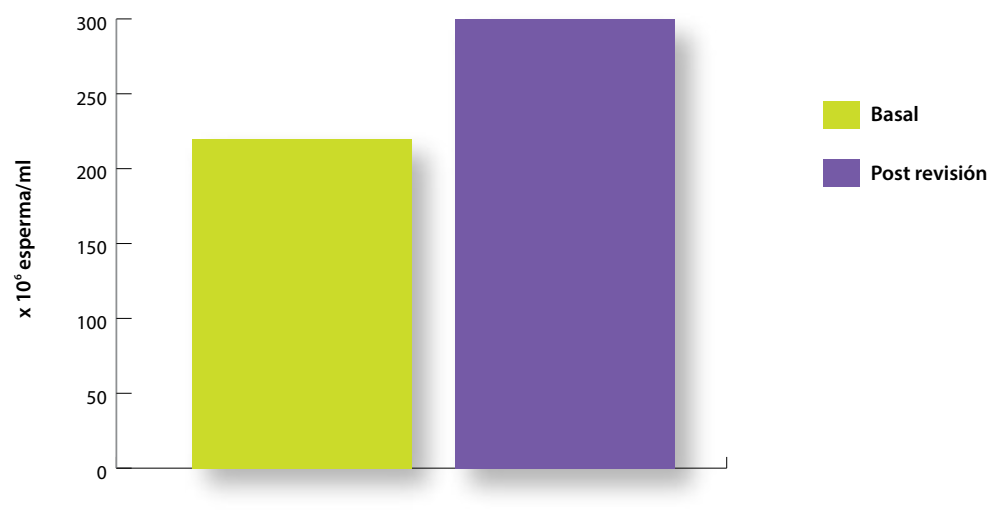

Fig. 3. Concentración de esperma $\left(x 10^{6}\right)$ durante el inicio y después de los procedimientos de reversión. La concentración de esperma volvió a los niveles basales después de la inversión. No hay diferencia significativa entre la línea de base y la reversión posterior.

La motilidad de los espermatozoides Se concluyó la necesidad de determinar en tampoco fue significativamente diferen- más investigaciones, si un período de tiemte al comparar la línea de base con la post po más largo permitiría la recuperación versión $(p<0.17)$ (figura 4). La progresión completa de las estructuras vasculares o si hacia adelante fue significativamente me- se necesitan procedimientos de enjuague nor después del procedimiento de rever- mejorados para eliminar completamente el sión (Wilcoxon $Z=2.37, p<0.018$ ) con Vasalgel que conduzca al retorno de la esuna línea de tendencia positiva $(R 2=0.90)$. permorfología normal. ${ }^{7}$

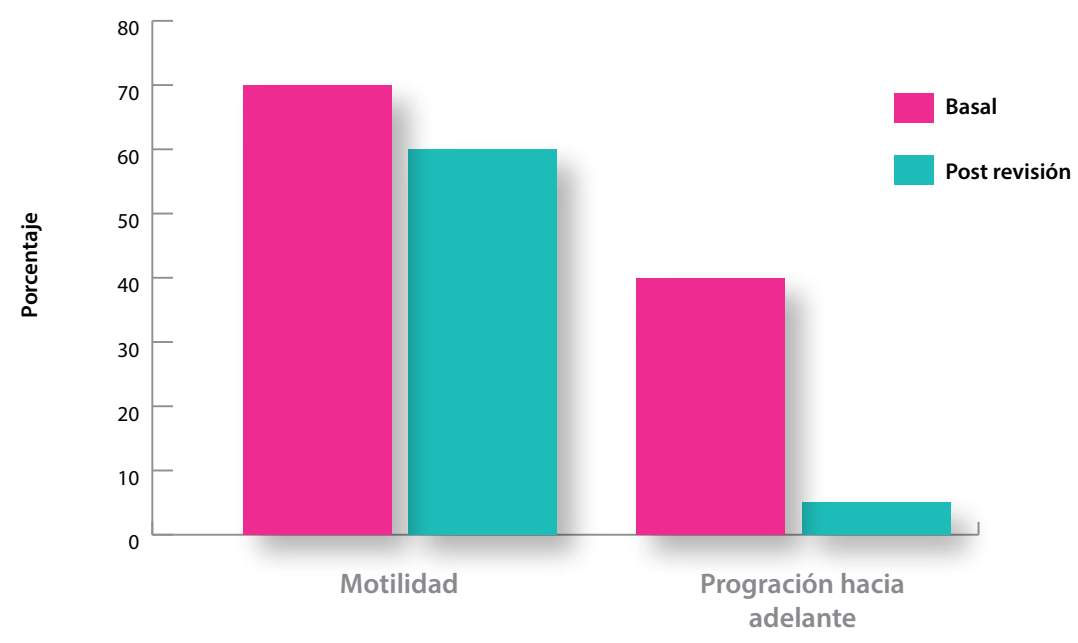

Fig. 4. Motilidad espermática y porcentaje de progresión hacia adelante al inicio del estudio y después de los procedimientos de reversión. La motilidad promedio volvió a los niveles basales después de la reversión del dispositivo. La progresión hacia adelante fue significativamente menor después de la reversión del dispositivo $(p<0.02){ }^{6}$ 


\section{Análogo de bisdicloroacetildiaminas (DBAD)}

En estudios se ha demostrado que la deficiencia de vitamina $A$ y su metabolismo activo es reconocido como en su papel en la esterilidad masculina. ${ }^{29}$ La vía del ácido retinoico (RA) que incluye la conversión de retinol a retinal y finalmente a RA, proporciona lugares donde se pueden aplicar inhibidores o antagonistas para detener la síntesis de la RA y detener la espermatogénesis utilizando un análogo de bisdicloroacetildiamina (DBAD). En estudio WIN19,446 se trató a 60 hombres en seguimiento de un año, el fármaco fue bien tolerado y eficaz. ${ }^{29,30} \mathrm{Sin}$ embargo, el consumo de alcohol indujo una reacción de disulfiram (antabuse) severa, causando la terminación del desarrollo del medicamento.

La reacción disulfiram se debe a la inhibición de deshidrogenasa $2(A L D H 2)$. Esta enzima desintoxica aldehído el metabolismo del alcohol y la inhibición por DBAD produce acumulación de aldehído tóxico. ${ }^{2} \mathrm{Re}$ cientemente se han desarrollado inhibidores covalentes y no covalentes de moléculas pequeñas de ALDH1A2. Las estructuras de co-cristales de rayos $X$ de los inhibidores proporcionan el marco estructural para el diseño de inhibidores potentes y selectivos de ALDH1A2; sin embargo, no se han obtenido resultados concluyentes. ${ }^{2}$ Por otra parte se ha analizado otra opción con un antagonista del receptor de ácido pan-retinoico BMS-189453 demostró la inhibición reversible de la espermatogénesis en un modelo de ratón. ${ }^{29}$

\section{Inhibición de las proteínas específicas del bromodominio testicular}

Las proteínas específicas del bromodominio testicular (BRDT) son proteínas de cromatina específicas del testículo que se une específicamente a la histona $\mathrm{H} 4$ acetilada en 'Lys-5' y 'Lys-8' (H4K5ac y H4K8ac, respectivamente) y desempeña un papel clave en la espermatogénesis ya que fomenta la compactación cromosómica para la primera división meiótica en la producción de esperma. Esta reorganización de la cromatina protege la información genética, y la ubicación y el estado de modificación de las histonas restantes preparan el genoma para la reactivación después de la fertilización. ${ }^{10}$ Además, no sólo actúa en la primera división meiótica, si no que también puede facilitar la compactación de la cromatina post meiótica al unirse a las colas de histona acetiladas, facilitando el reemplazo de las histonas hiperacetiladas con proteínas altamente básicas específicas de esperma conocidas como protaminas. ${ }^{31,32}$ En diferentes experimentos esto ha sido comprobado, inhibiendo la proteína BRDT en ratones machos que maduran totalmente sanos pero estériles, concluyendo que esta proteína es esencial para la espermatogénesis. ${ }^{33}$

La molécula utilizada para la inhibición es una tienotriazolodiazepina llamada JQ1, es un potente inhibidor de la familia BET de proteínas de bromodominio que incluyen BRD2, BRD3, BRD4 y la proteína BRDT. Esta molécula se une de manera competitiva a BRDT, evitando el modelado de cromatina requerido para la espermatogénesis. ${ }^{10,33}$ En un estudio en el que se utilizaron ratones fue demostrada la reversibilidad de la fertilidad después del uso continuo de JQ1, después de un mes de la suspensión de dicha molécula, además no sólo que se restableció la fertilidad, sino que el tamaño de la camada y las crías nacidas después del tratamiento estaban dentro de la normalidad. ${ }^{32}$

Cabe resaltar que el BRDT se expresa sólo en espermatocitos de mediano a más tardío desarrollo y no en espermatogonias de división mitótica; entonces, un inhibidor específico de BRDT no afectaría a la población de células madre espermatogoniales, haciendo que cualquier inhibición de BRDT de molécula pequeña sea reversible y no produzca efectos nocivos sobre las espermátides maduras subsiguientes. ${ }^{10,13,33-35}$ 


\section{RISUG ${ }^{\circledR}$}

Se trata de una inhibición reversible de esperma bajo guía (RISUG), muy similar a la vasectomía, pero en lugar de cauterizar y cortar el vaso deferente ${ }^{36}$ (figura 5), es un medicamento inyectable en los conductos deferentes, que consiste en un copolímero de anhídrido maleico de estireno (SMA) reaccionado químicamente con dimetilsulfóxido (DMSO). La dosis que es utilizada en algunos estudios es $60 \mathrm{mg}$ de SMA en complejo químico con $120 \mu \mathrm{l}$ de DMSO. ${ }^{8}$ El DMSO es elegido como vehículo solvente, se expone bilateralmente el conducto deferente con el sitio de inyección original y se inyecta la difusión lenta el DMSO, ${ }^{36,37}$ ya que ayuda a la penetración del polímero en los pliegues de la pared interna del conducto deferente y mejora su retención, además una parte de SMA se convierte en ácido estireno maleico, el cual neutraliza el $\mathrm{pH}$ alcalino de DMSO. ${ }^{38}$
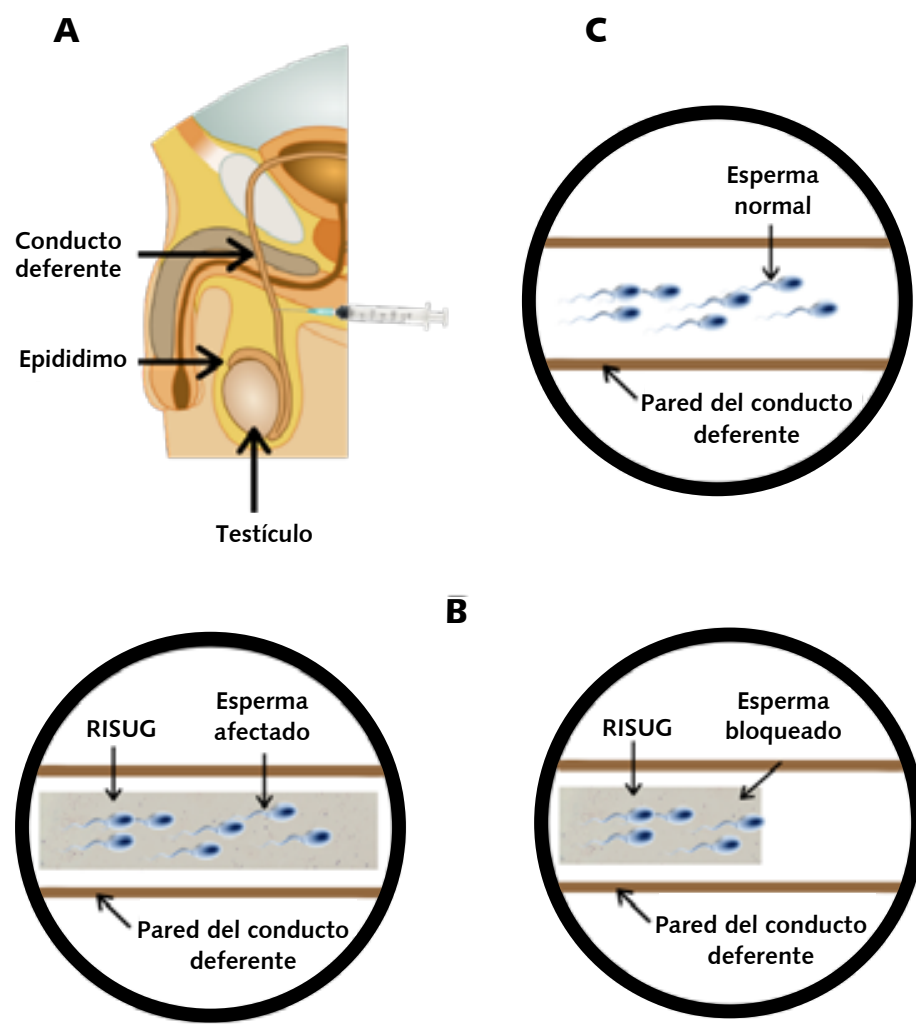

$\overline{\mathbf{B}}$

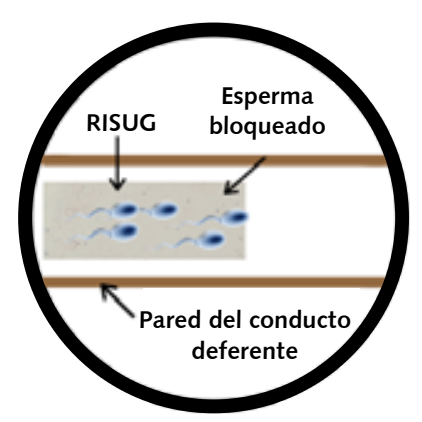

Fig. 4. RIGUG: modelo de acción. (A) Se expone el vaso de la región inguinal y se inyecta RISUG en ambos vasos deferentes hacia la región distal mediante una micro jeringa. (B) RISUG recubre la pared del conducto deferente bloqueando el movimiento de los espermatozoides. (C) Reversión completa obtenida después de inyectar DMSO / NAHCO3 bilateralmente, componente de lavado de RISUG. ${ }^{38}$

Se ha propuesto que el complejo de SMA y DMSO actúa a través de la oclusión de los conductos deferentes, disminución del $\mathrm{pH}$ que afecta directamente a la movilidad de los espermatozoides y el efecto de pertur- bación de la carga. Este último se explica debido que los daños en los espermatozoides debido a RISUG® son muy similares a los daños causados por el estrés oxidativo. La generación de exceso de especies reacti- 
vas de oxígeno (ROS) intracelulares o extracelulares tales como lo son $\mathrm{O}_{2}, \mathrm{H}_{2} \mathrm{O}_{2}$, $\mathrm{ROO}$ y $\mathrm{OH}$ están asociadas con muchos daños celulares, incluidos defectos morfológicos, fragmentación del ADN, peroxidación lipídica, disminución de la reacción del acrosoma y fertilización deteriorada. ${ }^{38}$

En un estudio en el cual se reclutaron 141 individuos, de los cuales sólo 133 recibieron la dosis completa de RISUG, los resultados encontrados fueron satisfactorios ya que se logró la azoospermia en todos los individuos, que va desde un mes hasta seis meses después del período de inyección. En el $82.7 \%$ de las personas, la azoospermia se logró dentro de los dos meses posteriores a la inyección, mientras que en el 17.3 por ciento restante, la azoospermia se logró durante los tres a seis meses posteriores a la inyección. ${ }^{8}$

Algunos de los efectos adversos encontrados son el aumento leve del escroto, a causa del edema difuso del tejido escrotal, en la primera semana después de la inyección en la mayoría de los individuos, el cual desapareció un mes después sin algún tratamiento adicional y nódulo escrotal en el sitio de inyección que también desapareció durante el período de seis meses en la mayoría de los individuos. . $^{8,36-38}$

En un estudio en el que se utilizó un modelo animal de rata, se evaluó el uso de $\mathrm{NaHCO}_{3}$ como solvente comparado con DMSO. Se expone bilateralmente el conducto deferente con el sitio de inyección original y se inyecta a difusión lenta el Na$\mathrm{HCO}_{3}$, el tapón disuelto es evidente por el flujo directo de $\mathrm{NaHCO}_{3}$. Solución alcalina ( $\mathrm{pH}$ 8-9), reacciona con RISUG y forma $\mathrm{CO}_{2}$, los iones de bicarbonato se reducen por naturaleza ácida de RISUG. Además, el $\mathrm{pH}$ alto aumenta la motilidad de los espermatozoides de forma gradual. La reversión con $\mathrm{NaHCO}_{3}$ resultó en una pronta reanudación de la fertilidad en comparación con DMSO y el procedimiento resultó exitoso y factible, además de seguro. ${ }^{36}$
RISUG parece ser un anticonceptivo masculino no hormonal prometedor para lograr un cambio en lo que se conoce de la anticoncepción masculina. En ensayos clínicos de fase I y fase II han confirmado su seguridad y eficacia anticonceptiva. ${ }^{38}$ Puede ser utilizado con su reversibilidad cuando sea necesario, incluso después de mucho tiempo, sin observar efectos adversos. ${ }^{37}$ Es un método en investigación reciente y muy prometedor para su aplicación.

\section{Efecto del calentamiento escrotal sobre la calidad del esperma}

La génesis espermática es un proceso dependiente de temperatura, la temperatura escrotal se mantiene por debajo de $2^{\circ} \mathrm{C}$ a $8^{\circ} \mathrm{C}$ de la temperatura corporal central. El factor inhibidor de la migración de macrófagos (MIF), es una citocina proinflamatoria la cual se encuentra altamente expresada en el epidídimo, y dicho aumento se ha asociado a pobre motilidad espermática. Sin embargo, se desconoce actualmente cómo es que el MIF influye en la función espermática y la apoptosis en los hombres. El factor de crecimiento epidérmico humano (EGF), se ha identificado en varios fluidos biológicos, fluido prostático y líquido seminal, y es una de las citocinas importantes que intervienen en un papel de la fertilidad. ${ }^{39}$

Recientemente se realizó un estudio en que se evaluó el efecto del calentamiento escrotal sobe la calidad del esperma. La concentración espermática que revelaron las muestras del estudio antes del calentamiento escrotal fue de $24-167 \times 10^{6}$, la tasa de motilidad fue del $30-95 \%$ y la proporción morfológica espermática normal fue del $13-45 \%$. Durante el primer mes del estudio, bajó a 0 la concentración espermática en un sujeto; al segundo mes, la duración del calentamiento escrotal se redujo de 40 a 30 minutos, la tasa de motilidad fue menor al $40 \%$ en 15 sujetos y la proporción morfológica normal fue inferior al $4 \%$ en seis sujetos. Después de un mes de recupera- 
ción, de haber suspendido el calentamiento escrotal, los parámetros evaluados comenzaron a ser normales gradualmente. Tres meses después de detener el calentamiento escrotal, la concentración media y la tasa de morfología normal fue similar, asimismo la tasa de motilidad fue menor a la que se registró antes de iniciar el tratamiento. 7,39

El factor inhibidor de la migración de macrófagos (MIF), factor de crecimiento epidérmico humano (EGF), L-carnitina (LC), evaluados antes, durante y después del calentamiento escrotal comparado en 30 sujetos mostraron diferencias estadísticamente significativas (tabla 2). No se identificaron efectos adversos después del tratamiento con calentamiento escrotal en ninguno de los pacientes. Sin embargo, se necesitan más estudios con un periodo de seguimiento superior al presente.

\section{Tabla 2}

\section{Parámetros de semen, DFI, HDS, MIF, EGF y L-carnitina analizados en diferentes puntos de tiempo (media \pm DE) ${ }^{39}$}

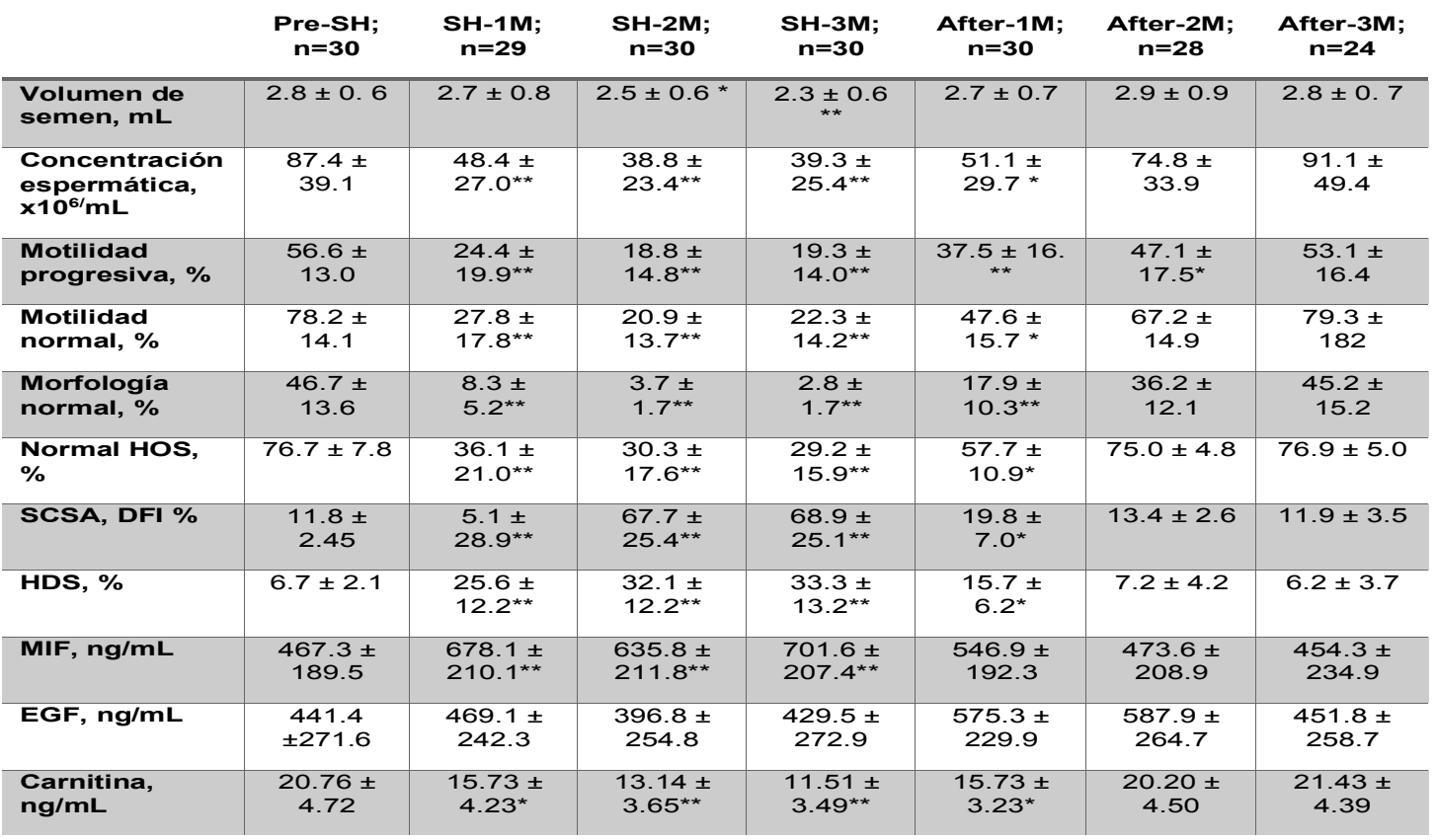

DFI, índice de fragmentación del ADN; EGF, factor de crecimiento epidérmico; HDS, alta estabilidad del ADN; HOS, hinchazón hipoosmótica; FOMIN, factor inhibidor de la migración; SCSA, ensayo de estructura de cromatina espermática; $S H$, escrotal calefacción.

$* P<0.05$, prueba t de muestras pareadas, antes de SH vs durante y después de SH.

** $P<0.01$, prueba t de muestras pareadas, antes de SH vs durante y después de SH

\section{Análogo 25 de ouabagenina}

El Na,K-ATPasa $\alpha 4$ es un transportador de $\mathrm{Na}{ }^{+}$y K ${ }^{+}$de membrana plasmática específica de testículo expresado en el flagelo de los espermatozoides. Se ha observado que la eliminación de $\mathrm{Na}, \mathrm{K}$-ATPasa $\alpha 4$ en ratones macho produce infertilidad completa, lo que la convierte en un objetivo atractivo para la anticoncepción..$^{40}$ El principio de acción de este método se encuentra en los 
inhibidores selectivos de la Na,K-ATPasa $\alpha 4$ y de la función espermática, los derivados de ouabaína se modificaron en la glicona (C3) y la lactona (C17) dominios. El análogo 25 de ouabagenina, que porta un resto benciltriazol en C17, es un inhibidor picomolar de $\mathrm{Na}, \mathrm{K}$-ATPasa $\alpha 4$, con un destacado perfil de selectividad de isoforma $\alpha 4$. En este modelo con ratas se observó una disminu- ción en la movilidad de los espermatozoides in vitro $e$ in vivo y potencial de membrana espermática afectado, $\mathrm{Ca}^{2+}$ intracelular, $\mathrm{pH}$ e hipermotilidad. El análogo de triazol es un inhibidor eficaz y selectivo de $\mathrm{Na}, \mathrm{K}$-ATPasa a4 y la función espermática; sin embargo, sigue en investigación para su uso anticonceptivo. ${ }^{40}$

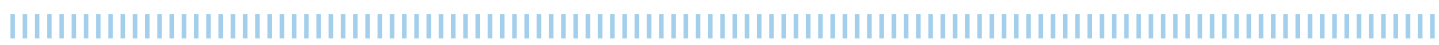

\section{Discusión}

Los condones masculinos forman parte esencial y única en el mercado como $A M$ de barrera, los WLM y WLC tienen la virtud de que no se necesita una erección para su colocación; ${ }^{5}$ sin embargo, su característica adhesiva puede ser incómoda o dolorosa para la población con vello corporal o hipersensibilidad, datos importantes que deberán ser considerados durante la consulta médica. Estos nuevos condones cumplen la meta innovadora y siguen protegiendo al usuario de infecciones de transmisión sexual.

Los AMH han tenido un amplio estudio en humanos en los últimos años, en el que destacan los realizados entornos a DMAU y Nest-T. Actualmente no existe un estudio clínico que compare ambos métodos. Pero se puede destacar que los efectos adversos similares son el acné, cambios de humor y aumento de peso relativo. ${ }^{9,12,22,25}$ Ambos presentan cambios en la libido ${ }^{2,25}$ y sólo en DMAU hay un porcentaje de pacientes con decrecimiento de erecciones. ${ }^{25}$ Se necesitan más estudios para determinar poblaciones específicas y sus comorbilidades que pue- dan desencadenar un efecto adverso severo con su uso.

Entre los AMNH estudiados, sólo RISUG y el calentamiento escrotal tienen estudios clínicos en seres humanos. 2,38,39 EPPIN, Vasalgel, DBAD, JQ1 y los análogos 25 de ouabagenina sólo se han estudiado, por el momento, en modelos animales. ${ }^{2,12}$ Aunque tienen la nobleza de no interferir directamente en el eje hipotálamo-hipofisario, se necesitan más investigación para determinar sus efectos adversos u otras aplicaciones médicas. El calentamiento escrotal no demostró efectos adversos, pero son necesarios más estudios en poblaciones más grandes para un seguimiento superior. Entonces, destaca RISUG como el mejor AMNH en estudió actualmente, su reversibilidad y seguridad corroborada en estudios fase I y II le permiten acercarse más al umbral de la accesibilidad general de la población. Su único inconveniente hasta el momento es el aumento leve del escroto por el edema escrotal difuso durante la primera semana posterior a la aplicación, pero que desaparece sin ninguna secuela.

\section{Conclusiones}

El romper con el esquema de opciones con los que cuenta la población masculina es un gran reto. Los condones masculinos son la herramienta de confianza que tiene una gran historia arraigada con sus usuarios. Al ser una población tan acostumbrada al uso de pocos medios de planificación familiar es muy difícil que acepten condones adhe- 
sivos sintéticos como los presentados, en especial en México. Los métodos $\mathrm{AMH}$ han demostrado ser efectivos en la bibliografía actual. En general, los efectos secundarios que se han observado son: acné, aumento de peso, cambios en el colesterol, disminuyendo HDL, LDL y colesterol total y cambios de humor. Sin embargo, es necesario demostrar la seguridad a largo plazo antes de considerar cualquier método para la aprobación reglamentaria. Los $\mathrm{AMNH}$, aunque prometen evitar los efectos secundarios de los hormonales, se encuentran en su mayoría en estudios preclínicos. El reto de los anticonceptivos masculinos hormonales y no hormonales es demostrar un fuerte perfil de seguridad. Son necesarios estudios de todos estos anticonceptivos masculinos en población latinoamericana o mexicana. Siendo realistas, pasarán varios años antes de que uno de estos productos pueda llegar a nuestro país, pues se requieren ensayos a largo plazo con un número suficiente de parejas que superan a las muestras de los diversos estudios presentados.

\section{Bibliografía}

1. Sundaram A, Vaughan B, Kost K. Contraceptive Failure in the United States?: Estimates from the 2006 - 2010. Perspect Sex Reprod Health. 2017;49(1):716.

2. Long JE, Lee MS, Blithe DL. Male Contraceptive Development: Update on Novel Hormonal and Nonhormonal Methods. Clin Chem [Internet]. 2019 Jan 1;65(1):153-60. Available from: https://academic. oup.com/clinchem/article/65/1/153/5607910

3. Vera Cruz G, Humeau A, Moore PJ, Mullet E. Identifying determinants of Mozambican men's willingness to use a male contraceptive pill. Eur J Contracept Reprod Heal Care [Internet]. 2019 Jul 4;24(4):266-73. Available from: https://www.tandfonline.com/doi/ full/10.1080/13625187.2019.1630816

4. Thummalachetty $N$, Mathur $S$, Mullinax $M$, DeCosta K, Nakyanjo N, Lutalo $T$, et al. Contraceptive knowledge, perceptions, and concerns among men in Uganda. BMC Public Health [Internet]. 2017 Dec 10;17(1):792. Available from: http://bmcpublichealth.biomedcentral.com/articles/10.1186/ s12889-017-4815-5.

5. Ting CY, Ting RS-K, Lim CJ, King TL, Ting $H$, Gerofi J. Pilot study on functional performance and acceptability of two new synthetic adhesive male condoms (Wondaleaf): a randomized cross-over trial. Contraception [Internet]. 2019 Jul;100(1):65-71. Available from: https://linkinghub.elsevier.com/retrieve/pii/ S0010782419300587

6. Waller D, Bolick D, Lissner E, Premanandan C, Gamerman G. Reversibility of VasalgelTM male contraceptive in a rabbit model. Basic Clin Androl [Internet]. 2017 Dec 5;27(1):8. Available from: http:// bacandrology.biomedcentral.com/articles/10.1186/ s12610-017-0051-1

7. Thirumalai A, Page ST. Male Hormonal Contraception. Annu Rev Med [Internet]. 2020 Jan 27;71(1):17-31.
Available from: https://www.annualreviews.org/ doi/10.1146/annurev-med-042418-010947

8. Sharma RS, Mathur AK, Singh R, Das HC, Singh GJ, Toor DPS, et al. Safety \& efficacy of an intravasal, one-time injectable \& non-hormonal male contraceptive (RISUG): A clinical experience. Indian J Med Res. 2019 Jul;150(1):81-6.

9. Zitzmann $M$, Rohayem J, Raidt J, Kliesch S, Kumar $N$, Sitruk-Ware $R$, et al. Impact of various progestins with or without transdermal testosterone on gonadotropin levels for non-invasive hormonal male contraception: a randomized clinical trial. Andrology [Internet]. 2017 May;5(3):516-26. Available from: http://doi.wiley.com/10.1111/andr.12328

10. Wisniewski A, Georg Gl. BET proteins: Investigating BRDT as a potential target for male contraception. Bioorg Med Chem Lett [Internet]. 2020 Mar 15;30(6):126958. Available from: https://linkinghub.elsevier.com/retrieve/pii/ S0960894X20300111

11. O'Rand MG, Hamil KG, Adevai T, Zelinski M. Inhibition of sperm motility in male macaques with EP055, a potential non-hormonal male contraceptive. Schlatt S, editor. PLoS One [Internet]. 2018 Apr 19;13(4):e0195953. Available from: https:// dx.plos.org/10.1371/journal.pone.0195953

12. Reynolds-Wright JJ, Anderson RA. Male contraception: where are we going and where have we been? BMJ Sex Reprod Heal [Internet]. 2019 Oct;45(4):23642. Available from: http://jfprhc.bmj.com/lookup/ doi/10.1136/bmjsrh-2019-200395

13. Zdrojewicz Z, Kasperska K, Lewandowska M. Male contraception - the current state of knowledge. Pol Merkur Lekarski. 2016 Aug;41(242):111-4.

14. Page ST, Amory JK. Male hormonal contraceptive - are we there yet? Nat Rev Endocrinol [Internet] 2018 Dec 15;14(12):685-6. Available from: http:// www.nature.com/articles/s41574-018-0111-4

15. Wang C, Festin MPR, Swerdloff RS. Male Hormonal 
Contraception: Where Are We Now? Curr Obstet Gynecol Rep. 2016;5(1):38-47.

16. Wang C, Sitruk-Ware R, Serfaty D. It is time for new male contraceptives! Andrology [Internet]. 2016 Sep;4(5):773-5. Available from: http://doi.wiley. com/10.1111/andr.12251

17. Ross J, Hardee K. USE OF MALE METHODS OF CONTRACEPTION WORLDWIDE. J Biosoc Sci [Internet]. 2017 Sep 28;49(5):648-63. Available from: https://www.cambridge.org/core/product/identifier/S0021932016000560/type/journal_article

18. Yuen F, Thirumalai A, Pham C, Swerdloff RS, Anawalt $B D$, Liu PY, et al. Daily Oral Administration of the Novel Androgen 11?-MNTDC Markedly Suppresses Serum Gonadotropins in Healthy Men. J Clin Endocrinol Metab [Internet]. 2020 Mar 1;105(3):e83547. Available from: https://academic.oup.com/ jcem/article/105/3/e835/5715395

19. Ilani N, Roth MY, Amory JK, Swerdloff RS, Dart C, Page ST, et al. A New Combination of Testosterone and Nestorone Transdermal Gels for Male Hormonal Contraception. J Clin Endocrinol Metab [Internet]. 2012 Oct;97(10):3476-86. Available from: http://10.0.4.186/jc.2012-1384

20. Anawalt BD, Roth MY, Ceponis J, Surampudi V, Amory JK, Swerdloff RS, et al. Combined nestorone-testosterone gel suppresses serum gonadotropins to concentrations associated with effective hormonal contraception in men. Andrology [Internet]. 2019 Nov 10;7(6):878-87. Available from: https://onlinelibrary.wiley.com/doi/abs/10.1111/andr.12603

21. Mahabadi V, Amory JK, Swerdloff RS, Bremner WJ, Page ST, Sitruk-Ware R, et al. Combined Transdermal Testosterone Gel and the Progestin Nestorone Suppresses Serum Gonadotropins in Men. J Clin Endocrinol Metab [Internet]. 2009 Jul 1;94(7):231320. Available from: https://academic.oup.com/ jcem/article/94/7/2313/2596524

22. Attardi BJ, Hild SA, Reel JR. Dimethandrolone Undecanoate: A New Potent Orally Active Androgen with Progestational Activity. Endocrinology [Internet]. 2006 Jun 1;147(6):3016-26. Available from: https://academic.oup.com/endo/ article/147/6/3016/2879734

23. Attardi BJ, Marck BT, Matsumoto AM, Koduri S, Hild SA. Long-Term Effects of Dimethandrolone 17 -Undecanoate and 11 -Methyl-19-Nortestosterone 17 -Dodecylcarbonate on Body Composition, Bone Mineral Density, Serum Gonadotropins, and Androgenic/Anabolic Activity in Castrated Male Rats. J Androl [Internet]. 2011 Mar 1;32(2):183-92. Available from: http://doi.wiley.com/10.2164/jandrol.110.010371

24. Ayoub R, Page ST, Swerdloff RS, Liu PY, Amory JK, Leung $A$, et al. Comparison of the single dose pharmacokinetics, pharmacodynamics, and safety of two novel oral formulations of dimethandrolone undecanoate (DMAU): a potential oral, male contraceptive. Andrology [Internet]. 2017 Mar 1;5(2):278-85. Available from: http://doi.wiley.com/10.1111/ andr.12303

25. Thirumalai A, Ceponis J, Amory JK, Swerdloff R, Surampudi V, Liu PY, et al. Effects of 28 Days of
Oral Dimethandrolone Undecanoate in Healthy Men: A Prototype Male Pill. J Clin Endocrinol Metab [Internet]. 2019 Feb 1;104(2):423-32. Available from: https://academic.oup.com/jcem/article/104/2/423/5105935

26. O'Rand MG, Silva EJR, Hamil KG. Non-hormonal male contraception: A review and development of an Eppin based contraceptive. Pharmacol Ther. 2016 Jan;157:105-11.

27. Roth MY, Page ST, Bremner WJ. Male hormonal contraception: looking back and moving forward. Andrology [Internet]. 2016 Jan 1;4(1):4-12. Available from: http://doi.wiley.com/10.1111/andr.12110

28. Mariani NAP, Camara AC, Silva AAS, Raimundo TRF, Andrade JJ, Andrade AD, et al. Epididymal protease inhibitor (EPPIN) is a protein hub for seminal vesicle-secreted protein SVS2 binding in mouse spermatozoa. Mol Cell Endocrinol [Internet]. 2020 Apr;506:110754. Available from: https://linkinghub. elsevier.com/retrieve/pii/S030372072030054X

29. Chung SSW, Wang $X$, Wolgemuth DJ. Prolonged Oral Administration of a Pan-Retinoic Acid Receptor Antagonist Inhibits Spermatogenesis in Mice With a Rapid Recovery and Changes in the Expression of Influx and Efflux Transporters. Endocrinology [Internet]. 2016 Apr;157(4):1601-12. Available from: http://10.0.4.186/en.2015-1675.

30. Roth MY, Amory JK. Beyond the Condom: Frontiers in Male Contraception. Semin Reprod Med. 2016 Mar 4;34(3):183-90.

31. Gaucher J, Boussouar F, Montellier E, Curtet S, Buchou T, Bertrand $S$, et al. Bromodomain-dependent stage-specific male genome programming by Brdt. EMBO J [Internet]. 2012 Oct 3;31(19):3809-20. Available from: http://emboj.embopress.org/cgi/ doi/10.1038/emboj.2012.233

32. Bryant JM, Berger SL. Low-hanging fruit: targeting Brdt in the testes. EMBO J [Internet]. 2012 Oct 3;31(19):3788-9. Available from: http://emboj.embopress.org/cgi/doi/10.1038/emboj.2012.259

33. Berkovits $\mathrm{BD}$, Wolgemuth $\mathrm{DJ}$. The Role of the Double Bromodomain-Containing BET Genes During Mammalian Spermatogenesis. In: Current Topics in Developmental Biology [Internet]. Academic Press Inc.; 2013. p. 293-326. Available from: https://linkinghub.elsevier.com/retrieve/pii/ B9780124160248000118

34. Berkovits BD, Wolgemuth DJ. The first bromodomain of the testis-specific double bromodomain protein Brdt is required for chromocenter organization that is modulated by genetic background. Dev Biol [Internet]. 2011 Dec;360(2):358-68. Available from: https://linkinghub.elsevier.com/retrieve/pii/ S0012160611013005

35. Matzuk MM, McKeown MR, Filippakopoulos $P$, Li Q, Ma L, Agno JE, et al. Small-Molecule Inhibition of BRDT for Male Contraception. Cell [Internet]. 2012 Aug 17;150(4):673-84. Available from: https://linkinghub.elsevier.com/retrieve/pii/ S0092867412009294

36. Ansari AS, Hussain $M$, Khan SR, Lohiya NK. Relative suitability of DMSO and $\mathrm{NaHCO} 3$ for reversal of RISUG(R) induced long-term contraception. Andro- 


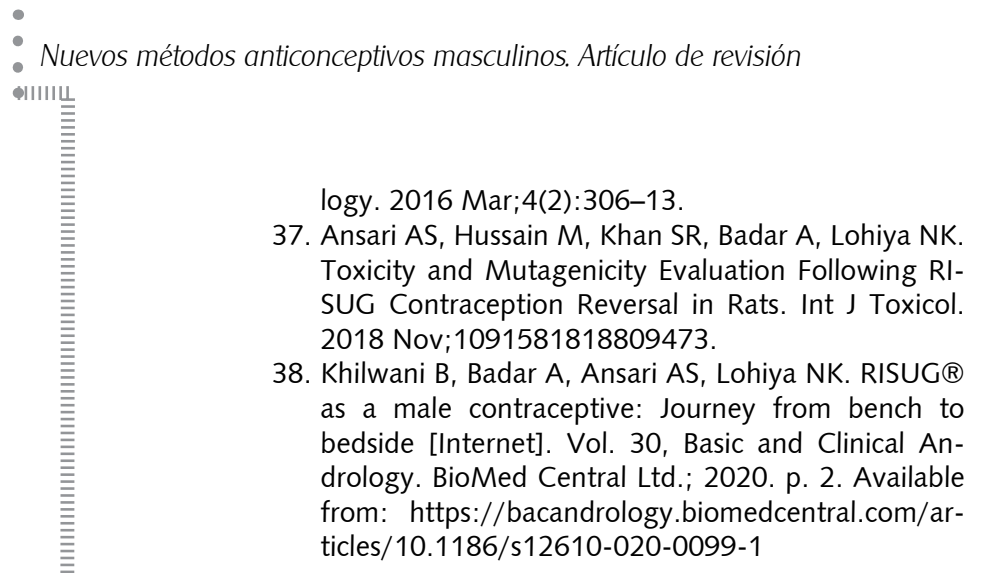

$\operatorname{ar} ; 4(2): 306-13$ SUG Contraception Reversal in Rats. Int J Toxicol. 2018 Nov; 1091581818809473 drology. BioMed Central Ltd : 2020. p. 2 . Available from: https://bacandrology.biomedcentral.com/articles/10.1186/s12610-020-0099-1
39. Zhang $M-H$, Zhai L-P, Fang Z-Y, Li A-N, Xiao W, Qiu Y. Effect of scrotal heating on sperm quality, seminal biochemical substances, and reproductive hormones in human fertile men. J Cell Biochem. 2018 Dec;119(12):10228-38.

40. Syeda SS, Sánchez G, Hong KH, Hawkinson JE, Georg $\mathrm{Gl}$, Blanco G. Design, Synthesis, and in Vitro and in Vivo Evaluation of Ouabain Analogues as Potent and Selective $\mathrm{Na}$, K-ATPase ?4 Isoform Inhibitors for Male Contraception. J Med Chem [Internet]. 2018 Mar 8;61(5):1800-20. Available from: https://pubs.acs. org/doi/10.1021/acs.jmedchem.7b00925 